University of Wollongong

Research Online

Australian Institute for Innovative Materials -

Papers

Australian Institute for Innovative Materials

$1-1-2015$

\title{
Harvesting temperature fluctuations as electrical energy using torsional and tensile polymer muscles
}

Shi Hyeong Kim

Hanyang University

Marcio Dias Lima

University of Texas

Mikhail E. Kozlov

University of Texas

Carter S. Haines

University of Texas

Geoffrey M. Spinks

University of Wollongong, gspinks@uow.edu.au

See next page for additional authors

Follow this and additional works at: https://ro.uow.edu.au/aiimpapers

Part of the Engineering Commons, and the Physical Sciences and Mathematics Commons

Research Online is the open access institutional repository for the University of Wollongong. For further information contact the UOW Library: research-pubs@uow.edu.au 


\title{
Harvesting temperature fluctuations as electrical energy using torsional and tensile polymer muscles
}

\begin{abstract}
Diverse means have been deployed for harvesting electrical energy from mechanical actuation produced by low-grade waste heat, but cycle rate, energy-per-cycle, device size and weight, or cost have limited applications. We report the electromagnetic harvesting of thermal energy as electrical energy using thermally powered torsional and tensile artificial muscles made from inexpensive polymer fibers used for fishing line and sewing thread. We show that a coiled $27 \mu$ m-diameter nylon muscle fiber can be driven by $16.7^{\circ} \mathrm{C}$ air temperature fluctuations to spin a magnetic rotor to a peak torsional rotation speed of 70000 $\mathrm{rpm}$ for over 300000 heating-cooling cycles without performance degradation. By employing resonant fluctuations in air temperature of $19.6^{\circ} \mathrm{C}$, an average output electrical power of $124 \mathrm{~W}$ per $\mathrm{kg}$ of muscle was realized. Using tensile actuation of polyethylene-based coiled muscles and alternating flows of hot and cold water, up to $1.4 \mathrm{~J}$ of electrical energy was produced per cycle. The corresponding per cycle electric energy and peak power output, per muscle weight, were $77 \mathrm{~J} \mathrm{kg-1}$ and $28 \mathrm{~W} \mathrm{~kg}-1$, respectively.
\end{abstract}

\section{Keywords}

polymer, tensile, torsional, muscles, energy, harvesting, electrical, fluctuations, temperature

Disciplines

Engineering | Physical Sciences and Mathematics

\section{Publication Details}

Kim, S. Hyeong., Lima, M. D., Kozlov, M. E., Haines, C. S., Spinks, G. M., Aziz, S., Choi, C., Sim, H. Jun., Wang, X., Lu, H., Qian, D., Madden, J. D W., Baughman, R. H. \& Kim, S. Jeong. (2015). Harvesting temperature fluctuations as electrical energy using torsional and tensile polymer muscles. Energy \& Environmental Science, 8 (11), 3336-3344.

\section{Authors}

Shi Hyeong Kim, Marcio Dias Lima, Mikhail E. Kozlov, Carter S. Haines, Geoffrey M. Spinks, Shazed Aziz, Changsoon Choi, Hyeon Jun Sim, Xuemin Wang, Hongbing Lu, Dong Qian, John D. W Madden, Ray H. Baughman, and Seon Jeong Kim 


\title{
Energy \& Environmental Science
}

CrossMark $\underset{\text { \& click for updates }}{\text { CrossMark }}$

Cite this: Energy Environ. Sci., 2015, 8, 3336

Received 17th July 2015

Accepted 17th September 2015

DOI: $10.1039 / c 5 e e 02219 c$

www.rsc.org/ees

\section{Harvesting temperature fluctuations as electrical energy using torsional and tensile polymer muscles $\uparrow$}

\author{
Shi Hyeong Kim, ${ }^{a}$ Márcio D. Lima, ${ }^{\mathrm{b}}$ Mikhail E. Kozlov, ${ }^{\mathrm{b}}$ Carter S. Haines, ${ }^{\mathrm{b}}$ \\ Geoffrey M. Spinks, ${ }^{c}$ Shazed Aziz, ${ }^{c}$ Changsoon Choi, ${ }^{a}$ Hyeon Jun Sim, ${ }^{a}$ \\ Xuemin Wang, ${ }^{d}$ Hongbing Lu, ${ }^{d}$ Dong Qian, ${ }^{d}$ John D. W. Madden, ${ }^{e}$ \\ Ray H. Baughman*b and Seon Jeong Kim*a
}

\begin{abstract}
Diverse means have been deployed for harvesting electrical energy from mechanical actuation produced by low-grade waste heat, but cycle rate, energy-per-cycle, device size and weight, or cost have limited applications. We report the electromagnetic harvesting of thermal energy as electrical energy using thermally powered torsional and tensile artificial muscles made from inexpensive polymer fibers used for fishing line and sewing thread. We show that a coiled $27 \mu \mathrm{m}$-diameter nylon muscle fiber can be driven by $16.7^{\circ} \mathrm{C}$ air temperature fluctuations to spin a magnetic rotor to a peak torsional rotation speed of $70000 \mathrm{rpm}$ for over 300000 heating-cooling cycles without performance degradation. By employing resonant fluctuations in air temperature of $19.6{ }^{\circ} \mathrm{C}$, an average output electrical power of $124 \mathrm{~W}$ per $\mathrm{kg}$ of muscle was realized. Using tensile actuation of polyethylene-based coiled muscles and alternating flows of hot and cold water, up to $1.4 \mathrm{~J}$ of electrical energy was produced per cycle. The corresponding per cycle electric energy and peak power output, per muscle weight, were $77 \mathrm{~J} \mathrm{~kg}^{-1}$ and $28 \mathrm{~W} \mathrm{~kg}^{-1}$, respectively.
\end{abstract}

\section{Broader context}

Low grade thermal energy from such sources as industrial waste streams, automobiles, and power plants is mostly wasted, since the present cost of recovering this low temperature thermal energy as electrical energy is too high. Improved methods for harvesting low grade thermal energy could provide an important new source of electrical energy, as well as a means to self-power autonomous sensors for the "Internet of Things". This initial work shows that artificial torsional and tensile muscles made from inexpensive fishing line and sewing thread can be used to harvest useful amounts of electrical power from lowtemperature waste energy sources. Coiled fibers made from $27 \mu \mathrm{m}$-diameter sewing thread generated electrical energy by torsionally rotating a magnetic rotor at speeds exceeding $70000 \mathrm{rpm}$. Using an air temperature fluctuation of only $19.6{ }^{\circ} \mathrm{C}, 124$ Watts of electrical energy per kilogram of muscle weight was harvested for possible use for autonomous sensors. By using tensile actuation, which can be upscaled for harvesting large amounts of waste thermal energy, coiled polyethylene muscles recovered $77 \mathrm{~J} \mathrm{~kg}^{-1}$ of electrical energy per cycle from streams of hot and cold water.

\footnotetext{
${ }^{a}$ Center for Bio-Artificial Muscle and Department of Biomedical Engineering, Hanyang University, Seoul 133-791, South Korea. E-mail: sjk@hanyang.ac.kr

${ }^{b}$ Alan G. MacDiarmid NanoTech Institute, University of Texas at Dallas, Richardson, TX 75083, USA. E-mail: ray.baughman@utdallas.edu

${ }^{c}$ Intelligent Polymer Research Institute, ARC Centre of Excellence for Electromaterials Science, University of Wollongong, Wollongong, New South Wales 2522, Australia

${ }^{d}$ Department of Mechanical Engineering, University of Texas at Dallas, Richardson, TX 75080, USA

${ }^{e}$ Department of Electrical and Computer Engineering and Advanced Material and Process Engineering Laboratory, University of British Columbia, Vancouver, British Columbia V6T 1Z4, Canada

$\dagger$ Electronic supplementary information (ESI) available: Materials, method and supplementary figures. See DOI: $10.1039 / \mathrm{c} 5 \mathrm{ee} 02219 \mathrm{c}$
}

\section{Introduction}

While low grade waste thermal energy is abundantly available from such sources as industrial waste streams and combustion engines, little of this thermal energy is harvested as electrical energy because present technologies are too expensive. This situation exists despite pioneering advances made over the last fifty years on developing energy harvesters based on thermoelectrics, ${ }^{1}$ pyroelectrics, ${ }^{2,3}$ ferroelectrics,${ }^{4}$ ferromagnets, ${ }^{5-7}$ and shape memory metals. ${ }^{8,9}$ We here harvest thermal energy as electrical energy by using the newly discovered thermally powered torsional and tensile actuation of artificial muscles made from inexpensive, highly-twisted fishing line or sewing thread. 
Our energy harvesting concept is simple: we use waste thermal energy to effect large stroke torsional or tensile actuation of an inexpensive polymer artificial muscle, which turns the rotor of an electric generator. Two embodiments of this concept are explored. Firstly, torsional actuation of an artificial muscle directly drives rotation of an attached magnet positioned within a generator. Secondly, tensile actuation of an artificial muscle rotates the shaft of a commercial electric motor, which is run in reverse to generate electricity.

The presently employed polymer fiber muscles benefit from decades of research on obtaining ultra-high strength, highly chain-aligned polymers for such sophisticated applications as anti-ballistic vests, and the fact that such polymer fibers are now so inexpensive that they can be used for fishing line and sewing thread. From the viewpoint of strength and modulus, we are doing terrible things to these monofilament fibers, by inserting such large twist that the polymer chains form helices and then further inserting so much twist that these helices form coils. However, for the purpose of making thermally powered artificial muscles, this twist insertion to produce coiling has wonderful benefits - enabling tensile contractions of over $50 \%$, load lifting capabilities that are 100 times higher than for a human muscle with the same length and weight, and the ability to generate about $27 \mathrm{~kW} \mathrm{~kg}^{-1}$ of average mechanical power during muscle contraction, about 84 times the peak output of a mammalian skeletal muscle. ${ }^{10}$ Powerful torsional actuation drives tensile actuation, ${ }^{10,11}$ and we here show that both tensile and torsional polymer muscle actuation can be usefully deployed to convert thermal energy to electrical energy.

\section{Results and discussion}

Torsional actuation in twisted fibers is linked to the anisotropic thermal expansion in highly-oriented, semi-crystalline polymer fibers, which causes length contraction, and correspondingly enhanced expansion of fiber diameter on heating for the investigated nylon 6,6 and polyethylene precursor fibers. ${ }^{12,13}$ Since twist insertion helically orients the polymer chains, an increase in fiber diameter, due to thermal expansion, causes the helix to untwist if the fibers are free to rotate. Additionally, the polymer chains contract during heating, further increasing the amount of fiber untwist that reversibly occurs during torsional actuation. In coiled fibers having the same handedness of polymer fiber twist and polymer fiber coiling, which are two-end tethered to prevent rotation and free to change length, fiber untwist brings coils closer together to provide contraction in coil length.

We first consider the direct use of thermally generated torsional actuation to electromagnetically provide the electrical energy needed to power autonomous sensors. The commercial nylon 6,6 fibers selected to make the torsional muscles had hair-like diameters of 27 to $127 \mu \mathrm{m}$, since these small diameters enabled fast responses to the rapidly changing air temperature. To make muscles, a motor was used to insert fiber twist while these precursor fibers were under a fixed tensile load that was sufficiently high to prevent fiber snarling (ESI $\dagger$ ). To obtain twisted, non-coiled muscles (hereafter called twisted muscles), a highly oriented precursor polymer fiber was twisted until just below the onset of coiling, which provided a polymer chain bias angle on the fiber surface of about $45^{\circ}$ with respect to the fiber direction (Fig. 1a) when the applied load was $26 \mathrm{MPa}$. Further twist insertion to initiate and complete coiling provided the investigated coiled muscles (Fig. 1b). Comparing the same lengths of untwisted precursor fiber, fully coiled fibers are 3-4 times shorter in length than fully twisted fibers that are not coiled. To set fiber twist, torsionally tethered muscle fibers were subsequently annealed isometrically (at constant length) in vacuum for 2 hours at $210{ }^{\circ} \mathrm{C}$, using zero applied strain. Unless otherwise indicated, mentioned muscle diameters are those of precursor non-twisted fiber and stresses are normalized with respect to the cross-sectional area of the precursor fiber, since the diameter of the coiled fibers is sensitive to the applied load and will change during actuation.

The magnetic rotor was located at the midpoint of a two segment fiber, whose ends were tethered to prevent rotation and translation (Fig. 1c and d). Using $\mathrm{Z}$ and $\mathrm{S}$ to represent
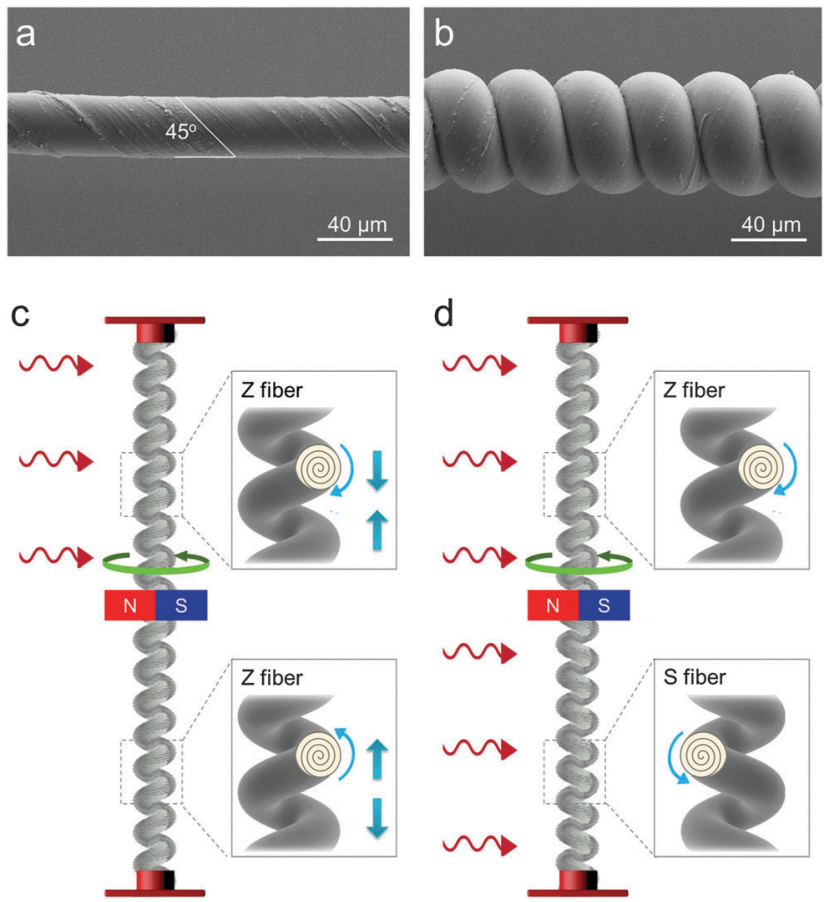

Fig. 1 Configurations for harvesting electrical energy from thermally powered torsional actuation of nylon 6,6 fibers. (a) Twisted muscle fiber prepared by inserting 8350 turns per $\mathrm{m}$ of twist into a $27 \mu \mathrm{m}$-diameter nylon 6,6 fiber to provide a bias angle of $45^{\circ}$. (b) Coiled muscle fiber prepared by inserting an additional 2850 turns per $\mathrm{m}$ of twist into the above twisted fiber. The outer diameter of the non-loaded coil is $62 \mu \mathrm{m}$ and its spring index is 1.14. (c) The homochiral ZZ fiber configuration used for torsional energy harvesting. The top half of the coiled fiber untwists during heating and contracts, while the unheated bottom half serves as a return spring by up-twisting and stretching. (d) The heterochiral SZ fiber configuration used for torsional energy harvesting. When fully-heated, the coiled $\mathrm{S}$ fiber and coiled $\mathrm{Z}$ fiber simultaneously untwist to provide the same direction torque on the rotor. Red fiber-end attachments prohibit both rotation and translation. 
right-handed and left-handed inserted twist, respectively, the configuration is either heterochiral (SZ or the equivalent ZS) or homochiral (ZZ or SS) depending upon the relative chirality of twist insertion in the two segments (which can be either coiled or non-coiled). For the ZZ configuration of Fig. 1c, symmetry breaking that enables torsional rotation is provided by heating only one segment - the heating-induced untwist of this segment drives corresponding up-twist of the unheated segment (which serves as a torsional return spring), providing torsional rotation of the magnetic rotor. The SZ configuration of Fig. 1d enables both yarn segments to equally contribute to rotor rotation when simultaneously heated. As previously demonstrated for wax-filled carbon nanotube hybrid yarns ${ }^{14,15}$ heated to above the melting temperature of the wax guest, the SZ configuration lacks full reversibility as a result of permanent, partial cancellation of the opposite twist in the two segments. However, the thermo-mechanical stability of the present thermally-set coiled SZ nylon muscles enabled highly reversible performance to about $90{ }^{\circ} \mathrm{C}$ while subject to the high torsional stresses needed to rapidly accelerate a high moment of inertia rotor to high speeds.

Torsional actuation of the magnetic rotor in response to fluctuating air temperature was measured using the signal induced on a miniature wire coil from a watch (see ESI, $\dagger$ and Fig. S1), which was separated at nearest approach by about $1.3 \mathrm{~mm}$ from the end of the rotating magnet. The number of positive voltage peaks measured on an oscilloscope provided the number of turns of the magnetic rotor during fiber untwist and subsequent retwist, and thereby the torsional stroke (herein reported in degrees per total length of the two muscle segments). The peak speed of the magnetic rotor in revolutions per minute (rpm), and thereby the peak kinetic energy, was calculated from the maximum frequency of the output voltage. Exposing the actuating segment or segments to a heat pulse from a hot air gun, which simulated turbulent air flow, provided the temperature increase that caused actuation, which was measured using a small thermocouple located by the muscle. Actuation and energy harvesting measurements were conducted either isobarically (under constant load) or isometrically (at constant length for the two-segment system). In all cases (ESI, $\uparrow$ Fig. S2), the applied load (for the isobaric case) and the applied strain (for the isometric case) were selected to optimize torsional actuation. For example, while the optimal applied strain for isometric torsional actuation of twisted SZ fibers was $0 \%$, it was $15 \%$ for coiled SZ fibers, since smaller strains resulted in inter-coil contact, providing inter-coil friction that interferes with torsional rotation.

The peak torsional rotation speed of the twisted SZ fiber and the coiled SZ fiber, which occurs during muscle cooling, increased by factors of 2.00 and 1.86 , respectively, when onesegment heating was changed to two-segment heating for isometric actuation under optimal applied strain (Fig. 2a and inset). This approximately two-fold advantage in maximum torsional rotation speed is understandable for this case of isometric actuation, where inter-coil contact is avoided, since the torque accelerating the rotor increases two-fold in going from half-heated to fully-heated heterochiral muscle. The mechanical torsional energy output is proportional to the square of peak rotation speed, which means that about four times higher mechanical energy can be outputted from a two segment length if both segments are heated, than is the case when only one segment is heated. Even when normalized to the two times higher input thermal energy needed for two segment heating, there is approximately a two-fold advantage in output mechanical energy for the fully-heated two-segment muscle system, which should translate to about twice the energy conversion efficiency. Since the coiled SZ fibers provide reversible performance for higher air temperature fluctuations $\left(\sim 65{ }^{\circ} \mathrm{C}\right.$, ESI, $\dagger$ Fig. S2) than do twisted SZ fibers $\left(\sim 40{ }^{\circ} \mathrm{C}\right.$ ), when heated to rapidly accelerate a rotor having a high moment of inertia, coiled SZ fibers were selected for electrical energy harvesting.

Both the peak torsional speed and the maximum torsional rotation angle of the magnetic rotor increased approximately linearly with a pulsed change in air temperature, $\Delta T$ (Fig. 2a). Hence, the output mechanical energy increases as $(\Delta T)^{2}$. Neglecting the dependence of heat capacity on temperature and mechanical load, this means that the thermal-to-mechanical energy conversion efficiency increases approximately linearly with $\Delta T$.

The torsional power output of fully-heated, coiled SZ torsional muscles was optimized through selection of fiber diameter and length, as well as the moment of inertia of the magnetic rotor. The results of Fig. $2 \mathrm{~b}$ and c show that increasing the moment of inertia of the rotor $(I)$ resulted in the expected decrease in peak rotor speed, but produced little or no change in the maximum torque on the rotor (calculated from the measured rotor acceleration) or the peak torsional kinetic energy of the rotor. This indicates that muscle-generated torque is effectively transmitted to the rotor, independent of the rotor's moment of inertia, and that the peak rotor speed is proportional to $\Gamma^{1 / 2}$, as theoretically predicted (see $\mathrm{ESI} \dagger$ ).

Elasticity theory predicts that the torsional and tensile work capability of polymer muscles should be scale invariant (see ESI $\dagger$ ), and this invariance has been experimentally demonstrated for tensile actuation of coiled polymer muscles. ${ }^{10}$ The invariance means that the maximum equilibrium work capacity of torsional actuation should be proportional to muscle volume and the equilibrium torsional stroke per muscle length should inversely depend on muscle diameter, as long as equivalent precursor fibers are identically coiled. Such identical coiling of different diameter nylon 6,6 fibers was realized by adjusting the static load applied during twist insertion, so that the applied stress (normalized to precursor fiber diameter) was kept constant. The amount of inserted twist ( $\tau$, in turns per meter) was scaled with fiber diameter $D$, so that $\tau D$ was kept constant. This scaling occurred automatically since twisted muscles and coiled muscles were twisted up to the point of coil nucleation and to the point of complete coiling, respectively, and these different transition points occurred at essentially the same $\tau D$ for different diameter nylon 6,6 fibers. As predicted by the scalability of the twist process under these conditions, the bias angle of the polymer chains on the fiber surface before the onset of coiling and the bias angle of the coils (measured relative to the twisted fiber direction and the radius of the 
a

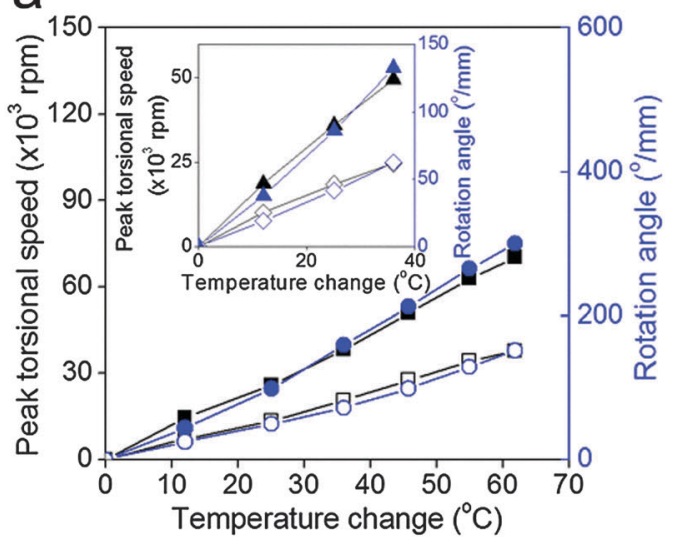

C

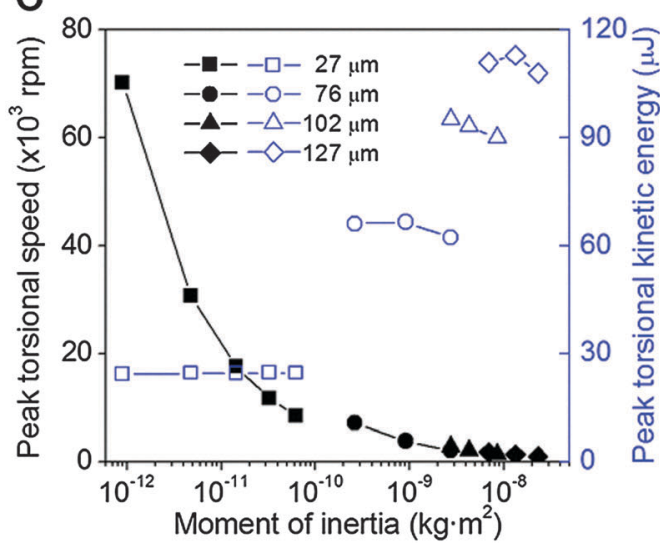

b

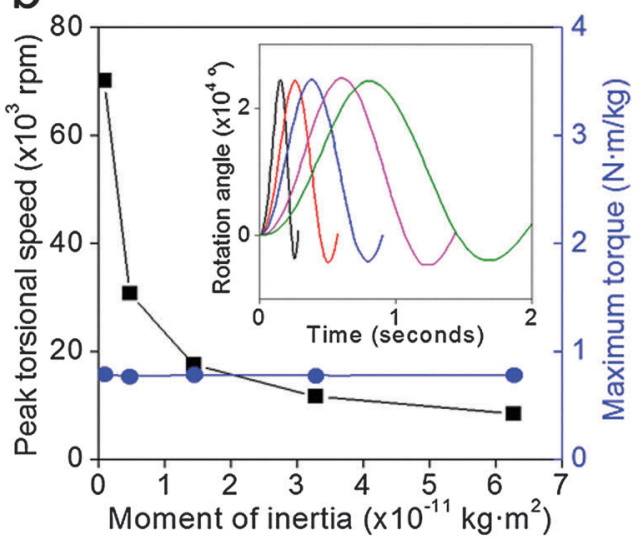

d

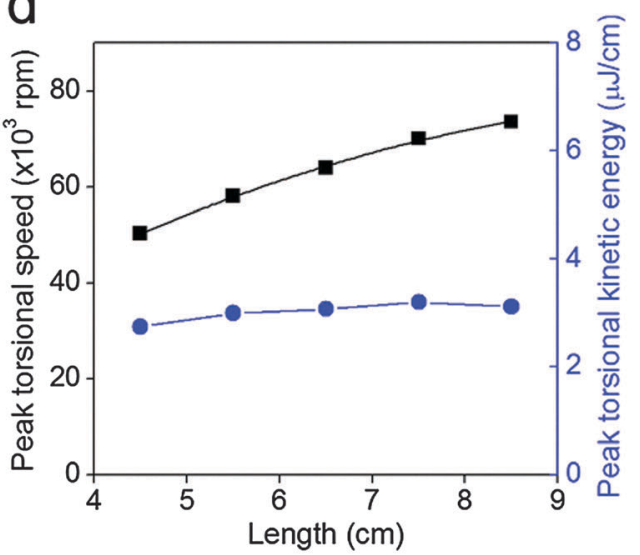

Fig. 2 Torsional isometric actuation of coiled SZ and twisted SZ fibre muscles resulting from a hot-air pulse. Unless otherwise indicated, the precursor fibre diameter was $27 \mu \mathrm{m}$, the magnetic rotor had a moment of inertia of $8.97 \times 10^{-13} \mathrm{~kg} \mathrm{~m}^{2}$, a $65^{\circ} \mathrm{C}$ change in air temperature was produced by the hotair pulse, and the total length of the two segments after stretching (by $15 \%$ for the coiled muscles and $0 \%$ for the twisted muscles) was $75 \mathrm{~mm}$. (a) Peak torsional speed (black symbols) and maximum rotation angle (blue symbols) versus the maximum air temperature change during actuation of a coiled SZ fibre, when heated over one-half its length (opened symbols) and over its entire length (closed symbols), respectively. Inset: Corresponding, analogously labeled, results for a half-heated and fully-heated, twisted SZ fibre. (b) Dependencies of peak torsional speed and maximum torque on the moment of inertia of the magnetic rotor for the above fully-heated, coiled SZ fibre. The torque was calculated from the initial rotor acceleration and the moment of inertia of the rotor. Inset: Rotation angle versus time (since onset of heat pulse) for rotors having the progressively increasing moments of inertia of the main figure. (c) Dependencies of peak torsional speed (closed black symbols) and peak torsional energy (opened blue symbols) on rotor moment of inertia for SZ fibres, which were made from equivalently-coiled precursor fibres having the diameters shown in the inset. (d) The length dependence of the peak torsional rotor speed (closed black squares) and the peak torsional rotor kinetic energy per muscle length (closed blue circles) produced by a coiled SZ fibre.

coiled fiber, respectively) were essentially independent of the diameter of the precursor fiber. ${ }^{10}$

Fig. $2 \mathrm{~d}$ shows that rotor torsional energy per muscle length is largely independent of muscle length, which is the predicted result from muscle scalability. However, the peak torsional kinetic energy of the coiled fiber does not increase quadratically with the diameter of the precursor fiber, as would be the case for equilibrium fiber torsional stroke. The likely explanation is that the temperature of the muscle core does not reach air temperature sufficiently rapidly for efficient harvesting of thermal energy as torsional kinetic energy unless the fiber diameter is sufficiently small, and this temperature lag is an increasing problem with increasing fiber diameter. The observed result of Fig. $2 \mathrm{c}$ is that the torsional kinetic energy increases approximately linearly with fiber diameter. This result can be explained if the heating rate for the fiber inversely depends on muscle diameter, which is reasonable since the surface area for heat flux is proportional to fiber diameter and the heat needed to produce a temperature change quadratically depends on fiber diameter.

The maximum torsional rotation speed (and therefore the maximum rotor kinetic energy) is realized during fiber retwist during fiber cooling (Fig. 3a), where stored strain energy produced by fiber untwist during fiber heating is converted to kinetic energy and added to the kinetic energy generated by fiber retwist during subsequent partial cooling. Hence, two average power densities are provided in Fig. $3 \mathrm{~b}$. These correspond to (1) the peak rotor kinetic energy for the initial fiber untwist (which can occur at or before fiber temperature reaches maximum value) and (2) the larger peak rotor kinetic energy on fiber retwist, where both are normalized by the time between the onset of the heating-pulse and the corresponding peak in rotor velocity. The results in Fig. $3 \mathrm{c}$ show the use of a small, 

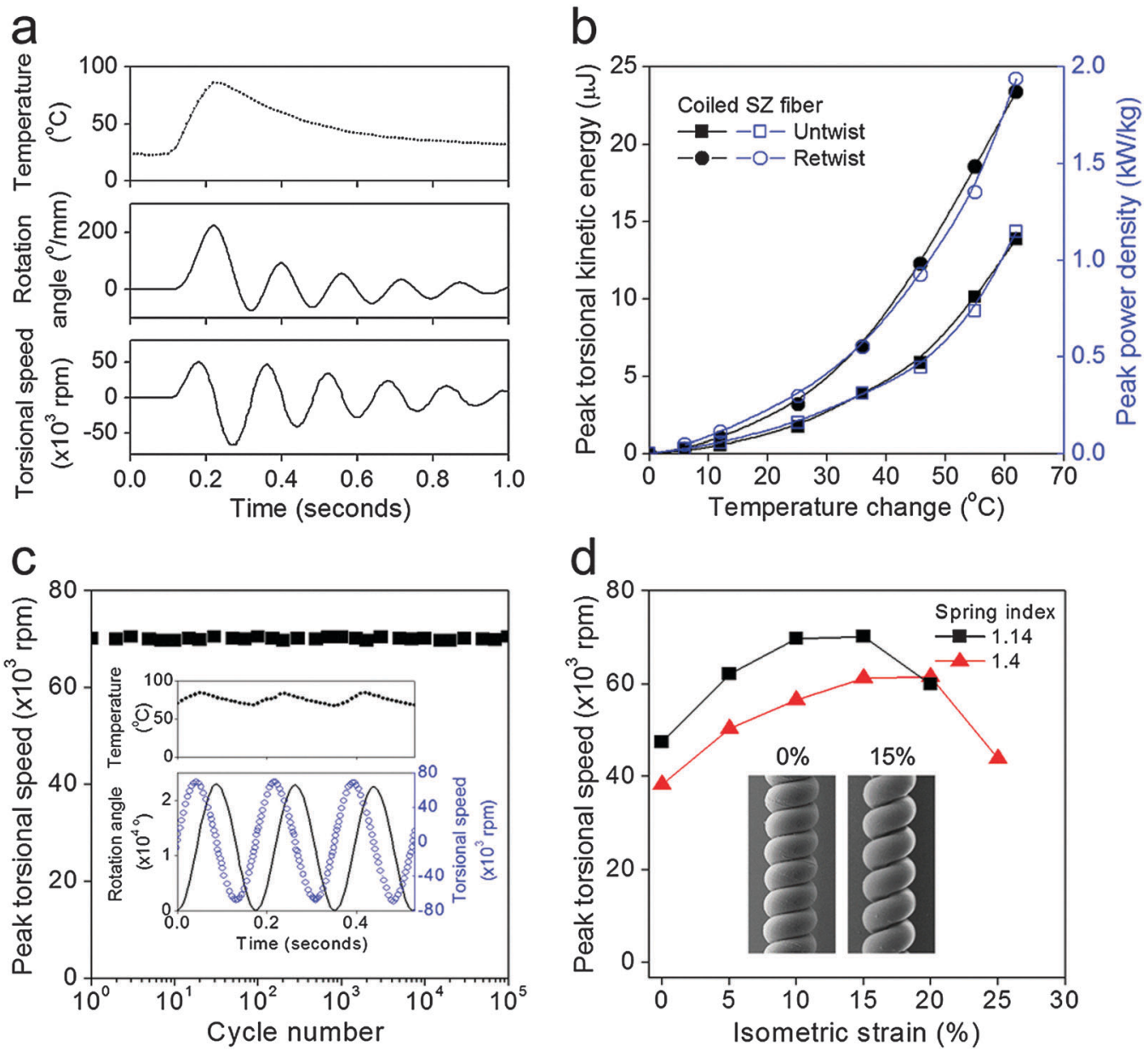

Fig. 3 Time, temperature, cycle number, and strain dependencies of torsional actuation for isometrically actuated, fully-heated, coiled SZ fibre. These results are for fully-heated muscles having $75 \mathrm{~mm}$ unloaded length, which were made by twist insertion into a $27 \mu \mathrm{m}$-diameter precursor nylon 6,6 fibre to produce complete coiling. Unless otherwise indicated, the moment of inertia of the magnetic rotor was $8.97 \times 10^{-13} \mathrm{~kg} \mathrm{~m}{ }^{2}$, the spring index was 1.14 , and the applied strain was $15 \%$. (a) The time dependencies of temperature, rotation angle and torsional speed following the application of one hot-air heat pulse. (b) Peak torsional kinetic energy (black symbols) and peak power density (blue symbols) versus temperature change during heating (square) and cooling (circle). (c) Data showing the invariance of peak torsional speed with cycle number. The insets show the time dependence of rotation angle, torsional speed, and the applied $5 \mathrm{~Hz}$ periodic temperature variation. (d) Dependence of peak torsional speed on applied strain for coiled SZ fibres having spring indexes of 1.14 (squares) and 1.40 (triangles), showing that this speed is maximized for $10-15 \%$ and $15-20 \%$ isometric strain, respectively. The inset provides SEM images of a coiled fibre with spring index 1.14 when under $0 \%$ and $15 \%$ strain.

periodically-fluctuating ambient temperature (see ESI $\uparrow$ ) to maintain continuous rotor oscillation for 300000 highly reversible twist-untwist cycles. As described later, when using resonant-frequency, small-amplitude temperature fluctuations for harvesting electrical energy, the figure insets show that a $\Delta T$ fluctuation of $16.7{ }^{\circ} \mathrm{C}$ at $\sim 5.5 \mathrm{~Hz}$ provides a periodic peak in torsional rotor speed of $\sim 70000 \mathrm{rpm}$, which is close to the peak rotor speed of $72000 \mathrm{rpm}$ in Fig. 3a during muscle retwist following a single hot air pulse of $\Delta T=63.9^{\circ} \mathrm{C}$.

For the isobaric case of a half-heated, coiled ZZ muscle, ESI, $\uparrow$ Fig. S4b shows that the torsional rotation angle during fiber untwist dramatically increases between $26 \mathrm{MPa}$ and $36 \mathrm{MPa}$, and is then nearly constant up to at least $70 \mathrm{MPa}$ stress. This dependence of torsional rotation angle on stress arises since friction due to inter-coil contact severely limits torsional rotation for $26 \mathrm{MPa}$ or lower load. Evidence for this inter-coil contact during most of the tensile stroke for $26 \mathrm{MPa}$ load (and part of the tensile stroke for $36 \mathrm{MPa}$ load) can be seen in the small thermal expansion for $26 \mathrm{MPa}$ load and the small thermal contraction for $36 \mathrm{MPa}$ load.

In contrast with the case of either isobarically or isometrically actuated one-half-heated ZZ fibers, segment lengths do not change during isometric actuation of fully-heated SZ muscles, so the axial position of the magnet with respect to the magnetic coil is invariant during thermal actuation. This invariance can be usefully deployed for minimizing the height of the magnetic generator, and for avoiding inter-coil contact of suitably strained muscle coils during thermal actuation. The effect of inter-coil contact at low applied strains appears in the strain dependence of isometric actuation (Fig. 3d), where strains of 10 to $15 \%$ and 15 to $20 \%$ are required to achieve peak torsional rotation speeds for fibers having spring indices of 1.14 and 1.4, respectively. For this fully-heated SZ fiber, the lowest spring index (which was obtained by applying the highest 
load during twist insertion) provided the smallest coil bias angle and the largest peak torsional speed (and therefore the highest kinetic energy available for the electromechanical harvesting of electrical energy).

Based on these optimization studies, we first selected an isometrically actuated, coiled, fully-heated SZ fiber with a low spring index of 1.14 for harvesting electrical energy from the torsional energy produced by applying a $65{ }^{\circ} \mathrm{C}$ hot air pulse. This coiled fiber was made from a $102 \mu \mathrm{m}$-diameter precursor fiber, since this fiber diameter was sufficient to rotate the below described high moment-of-inertia magnet to useful speeds, even though the weight of the magnetic rotor was 273 times the muscle weight $(3.73 \mathrm{mg})$. We harvested the thermally-produced torsional kinetic energy of a cylindrical neodymium-iron-boron rotor as electrical energy by surrounding this rotor coaxially with a six-mm-diameter, 3-phase, delta-type coil generator (Fig. 4a, see ESI, $\dagger$ for details). Uniformly heating the isometricallyactuated, coiled SZ fiber (which was $11 \mathrm{~cm}$ long after 15\% stretch) using a $65{ }^{\circ} \mathrm{C}$ air pulse, rotated the selected high moment-of-inertia magnet $\left(2.86 \times 10^{-9} \mathrm{~kg} \mathrm{~m}^{2}\right)$ to a peak torsional speed of $3330 \mathrm{rpm}$ when the generator was opencircuit. The three-phase alternating current (AC) output produced oscillating output voltages (Fig. 4b), with a maximum open-circuit, single-phase voltage of $0.16 \mathrm{~V}$. Unless otherwise indicated, the reported gravimetric and volumetric electrical energy and electrical power outputs for all electrical energy harvesters are normalized with respect to the weight or volume (including void volume) of the coiled muscle.

As shown by the data in Fig. 4(c), both the peak electrical power and the total generated electrical energy output per thermal cycle of the three-phase generator were maximized by attaching three external $6.8 \mathrm{ohm}$ resistors, one to each phase of the coil. This load optimization provided a total electrical energy output of $0.17 \mathrm{~mJ}$, a peak output power of $0.38 \mathrm{~mW}$, and an average output power of $0.094 \mathrm{~mW}$ during the 1.8 seconds needed for a thermal cycle (ESI, $\dagger$ Fig. S6a). The corresponding gravimetric energy density per cycle, peak power density, and average power density based on muscle weight are $45.3 \mathrm{~J} \mathrm{~kg}^{-1}, 102.1 \mathrm{~W} \mathrm{~kg}^{-1}$, and $25.2 \mathrm{~W} \mathrm{~kg}^{-1}$, respectively. Based on the total volume of the coiled muscle, which is 1.65 times higher than the fiber volume, these values are $32.5 \mathrm{~mJ} \mathrm{~cm}^{-3}, 73.5 \mathrm{~mW} \mathrm{~cm}^{-3}$, and $18.1 \mathrm{~mW} \mathrm{~cm}^{-3}$, respectively. Based on the total volume of the generator and coiled muscle, including all void space, the volumetric energy and power densities are $0.59 \mathrm{~mJ} \mathrm{~cm}^{-3}, 1.33 \mathrm{~mW} \mathrm{~cm}^{-3}$, and $0.33 \mathrm{~mW} \mathrm{~cm}^{-3}$, respectively. Using the area of the device when attached to a vertical wall (coiled fiber and magnet/generator cross-section), the areal electrical energy/cycle is $0.20 \mathrm{~mJ} \mathrm{~cm}{ }^{-2}$, the peak areal power is $0.45 \mathrm{~mW} \mathrm{~cm}^{-2}$, and the average areal power is $0.11 \mathrm{~mW} \mathrm{~cm}^{-2}$.

Fig. S6 (ESI, $\dagger$ ) shows that reducing the fiber diameter used to make the coiled muscle from the above $102 \mu \mathrm{m}$ to $27 \mu \mathrm{m}$ (and reducing the moment of inertia of the magnetic rotor 3190 fold) dramatically decreased the electrical energy output per cycle for a $65{ }^{\circ} \mathrm{C}$ change in air temperature from $170 \mu \mathrm{J}$ to $9.53 \mu \mathrm{J}$ (corresponding to gravimetric energies of $45.3 \mathrm{~J} \mathrm{~kg}^{-1}$ and $38.1 \mathrm{~J} \mathrm{~kg}^{-1}$, respectively). However, the peak electrical power output per muscle weight dramatically increased, from
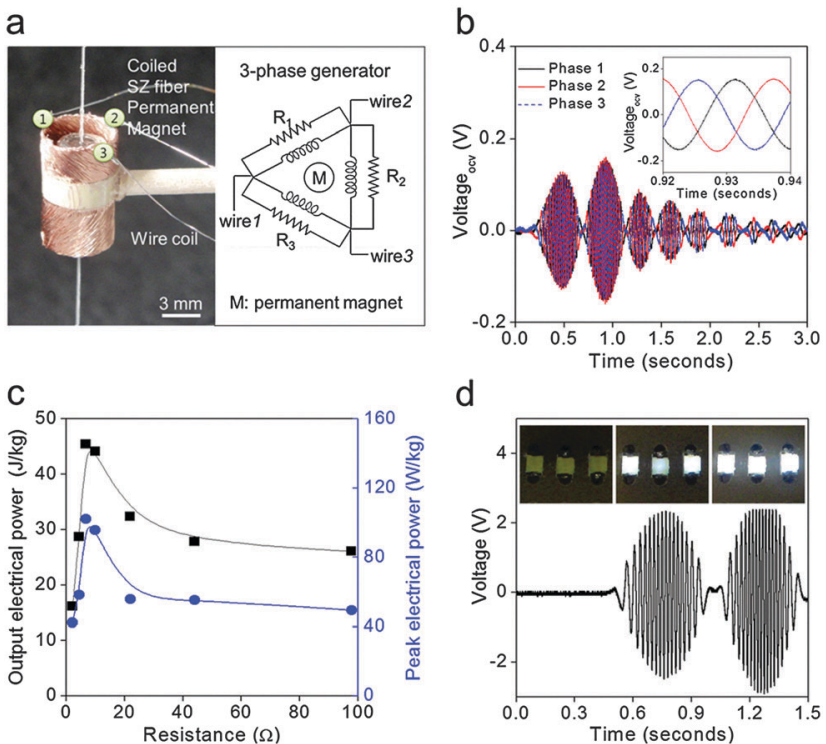

d

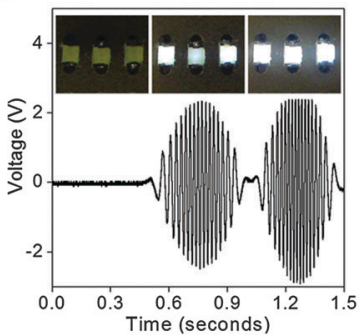

Fig. 4 Electricity generation from $65{ }^{\circ} \mathrm{C}$ temperature fluctuations using torsional rotation of a magnetic rotor driven by a fully-heated, coiled SZ fibre. (a) Photograph (left) of the deployed 3-phase electricity generator, which uses a coiled fibre muscle (made from a $102 \mu \mathrm{m}$-diameter nylon 6,6 fibre) to torsionally rotate a co-axial cylindrical neodymium magnet in a set of three coils. Equivalent load resistors were connected to each coil for determining output power, as shown in the schematic circuit diagram (right). (b) Open circuit voltage versus time for each of the three coils during heating with a single hot air pulse to $65^{\circ} \mathrm{C}$ above ambient temperature. Inset: Magnified time scale for voltage output for each of the three phases for one cycle of rotor rotation. (c) Dependence of the total electrical energy (per hot-air-pulse) and peak electrical power per muscle weight on the load resistance. (d) Demonstration of light-emitting diode (LED) operation induced by generated voltage. Voltages applied to the LEDs, after 18-fold amplification by step-up transformers. The minimum torsional speed needed for LED operation was 3330 rpm. Inset: The time sequence for one thermal pulse corresponding to LEDs off (left), on (middle, fibre untwist), and on (right, fibre retwist).

$102 \mathrm{~W} \mathrm{~kg}^{-1}$ to $576 \mathrm{~W} \mathrm{~kg}^{-1}$, while the average gravimetric electrical power increased much less, from $25.2 \mathrm{~W} \mathrm{~kg}^{-1}$ to $38.1 \mathrm{~W} \mathrm{~kg}^{-1}$. This giant peak gravimetric electrical power density for the $27 \mu \mathrm{m}$ fiber muscle likely arises principally from the much higher peak torsional rotation speed (70000 rpm) than for the much larger rotor coupled to the $102 \mu \mathrm{m}$ fiber muscle (3330 rpm). This ability to dramatically increase peak power density by using reduced moment of inertia magnetic rotors could be used to directly power intermittently used devices that need a high pulse of electrical power.

The electrical energy harvested from the rotor torsional kinetic energy produced by each $65{ }^{\circ} \mathrm{C}$ air-temperature pulse was sufficient to operate three $7.5 \mathrm{~mW}$ LEDs, when the voltage output of each of the three coils was increased 18 times using step-up transformers (Fig. $4 \mathrm{~d}$ and ESI, $\dagger$ Fig. S9 and Video S1). In another experiment (see ESI $\dagger$ ), which used a $27 \mu$ m-diameter nylon 6 precursor fiber, the generated AC voltage from repeated heating pulses was rectified to charge a $330 \mu \mathrm{F}$ capacitor (ESI, $\dagger$ Fig. S5). The voltage on the capacitor reached $1.15 \mathrm{~V}$ within 35 seconds (after 175 warm air pulses). Based on the $0.25 \mathrm{mg}$ muscle weight, the energy delivered to the capacitor, and the 
charging time, the average power delivered to the capacitor was $24.9 \mathrm{~W} \mathrm{~kg}^{-1}$, which is less than the above $38.1 \mathrm{~W} \mathrm{~kg}^{-1}$ delivered to an impedance-matched external resistor because of mismatched impedances and energy losses within the Fig. S5(a) (ESI $\dagger$ ) circuit used for capacitor charging.

While the above system was driven by successive rapid heating and cooling cycles, many sources of waste heat provide much slower temperature fluctuations. We adapted our system to harvest energy from a continuous flow of warm air by using a muscle-attached baffle to modulate the influx of hot air (ESI, $\dagger$ Fig. S10 and Video S2). The baffle was attached close to the bottom end of the fiber, where the torsional rotation angle is small. When warm air flowed through the open orifice, the fiber untwists, rotating both the magnet and the baffle. After 5 turns of the magnet, the baffle closed the orifice, allowing the fiber to cool back to its original torsional angle and reopen the orifice. This system automatically allows fiber heating and cooling driven by environmental hot air flow, thereby providing continuous AC voltage output from a constant temperature hot air source.

Fig. S7 and S8 (ESI, $\dagger$ ) show that the average electrical power output per muscle weight can be dramatically increased (while decreasing the temperature fluctuation needed for driving the muscle) by using a temperature fluctuation that is resonant with the torsional oscillation frequency of the magnetic rotor in the muscle system. These results are for the experimental configuration of Fig. S5a (ESI $\dagger$ ) for a $95 \mathrm{~mm}$-long coiled fiber weighing $0.25 \mathrm{mg}$, made from a $27 \mu \mathrm{m}$-diameter precursor fiber, and a load resistance of $6.4 \mathrm{k} \Omega$. Using a periodic air temperature fluctuation of $19.6{ }^{\circ} \mathrm{C}$ (from $67.6{ }^{\circ} \mathrm{C}$ to $87.2{ }^{\circ} \mathrm{C}$ ) at $4.8 \mathrm{~Hz}$ provided an output electrical energy of $25.9 \mathrm{~J} \mathrm{~kg}^{-1}$ per cycle and an average electrical power output of $124 \mathrm{~W} \mathrm{~kg}^{-1}$, while using a resonant temperature fluctuation of $8.2{ }^{\circ} \mathrm{C}$ (from $32.5{ }^{\circ} \mathrm{C}$ to $40.7{ }^{\circ} \mathrm{C}$ ) provided an output electrical energy of $5.35 \mathrm{~J} \mathrm{~kg}^{-1}$ per cycle and an average electrical power of $26.8 \mathrm{~W} \mathrm{~kg}^{-1}$. When normalized to $(\Delta T)^{2}$, the electrical energy per cycle for resonant harvesting using $\Delta T=19.6{ }^{\circ} \mathrm{C}$ and $8.2{ }^{\circ} \mathrm{C}$ (67.4 $\mathrm{mJ} \mathrm{K}^{-2} \mathrm{~kg}^{-1}$ and $79.6 \mathrm{~mJ} \mathrm{~K}^{-2} \mathrm{~kg}^{-1}$, respectively) are nearly equal, as are the average power densities $\left(323 \mathrm{~mW} \mathrm{~K}^{-2} \mathrm{~kg}^{-1}\right.$ and $399 \mathrm{~mW} \mathrm{~K} \mathrm{~K}^{-2} \mathrm{~kg}^{-1}$, respectively) for these temperatures. For comparison, non-resonant operation of the same muscle and energy harvesting system provided a $(\Delta T)^{2}$-normalized electrical energy-per-cycle and an average power of $9.0 \mathrm{~mJ} \mathrm{~K}{ }^{-2} \mathrm{~kg}^{-1}$ and $9.0 \mathrm{~mW} \mathrm{~K}^{-2} \mathrm{~kg}^{-1}$, respectively.

Our second type of generator for converting thermal energy to electrical energy utilized the tensile actuation of four parallel, coiled, polyethylene fiber muscles to rotate the shaft of a commercial electric motor in forward and reverse directions, as shown in Fig. 5a. These muscle fibers were connected through a flexible nylon fiber to a weight (which could be replaced by a fixed force-constant spring, in order to minimize weight and volume). This nylon fiber was wrapped around the shaft of an electric DC motor, whose output electrical energy and power during muscle contraction and expansion was measured by the voltage drop across a connected $10 \Omega$ resistor, which was empirically selected to maximize output electrical energy. The array of coiled muscles was encased in a flexible silicone tube to facilitate heat exchange using hot $\left(95^{\circ} \mathrm{C}\right)$ and cold $\left(25^{\circ} \mathrm{C}\right)$ water, which were cycled over the array at $0.125 \mathrm{~Hz}$.

The produced electrical energy depended on the tensile stress on the array (Fig. 5b), and reached $1.4 \mathrm{~J}$ per cycle at $18 \mathrm{MPa}$ applied tensile stress for a thermal cycle frequency of $0.125 \mathrm{~Hz}$, providing $175 \mathrm{~mW}$ of average output electrical power. The corresponding gravimetric densities (normalized to muscle weight) for electrical energy per cycle, peak power, and average power are $77 \mathrm{~J} \mathrm{~kg}^{-1}, 28 \mathrm{~W} \mathrm{~kg}^{-1}$, and $7.2 \mathrm{~W} \mathrm{~kg}^{-1}$, respectively. This gravimetric evaluation is very useful for comparing our tensile energy harvester with our non-resonant torsional energy harvesters, and is enabled by the similar temperature changes employed for energy harvesting: a $70{ }^{\circ} \mathrm{C}$ change in water temperature and a $65{ }^{\circ} \mathrm{C}$ change in air temperature, respectively. Interestingly, the obtained gravimetric electrical energy densities per thermal cycle are similar for the tensile harvester $\left(77 \mathrm{~J} \mathrm{~kg}^{-1}\right.$ ) and the torsional harvesters based on $102 \mu \mathrm{m}$ diameter (45.3 $\mathrm{J} \mathrm{kg}^{-1}$ ) and $27 \mu$ m-diameter $\left(38.1 \mathrm{~J} \mathrm{~kg}^{-1}\right.$ ) precursor fibers. These similar energies per cycle are reasonable; since we have previously shown that fiber untwist drives tensile actuation, and that similar mechanical work can be accomplished during untwisting of a twisted (non-coiled) muscle or tensile contraction of a coiled muscle. ${ }^{10}$
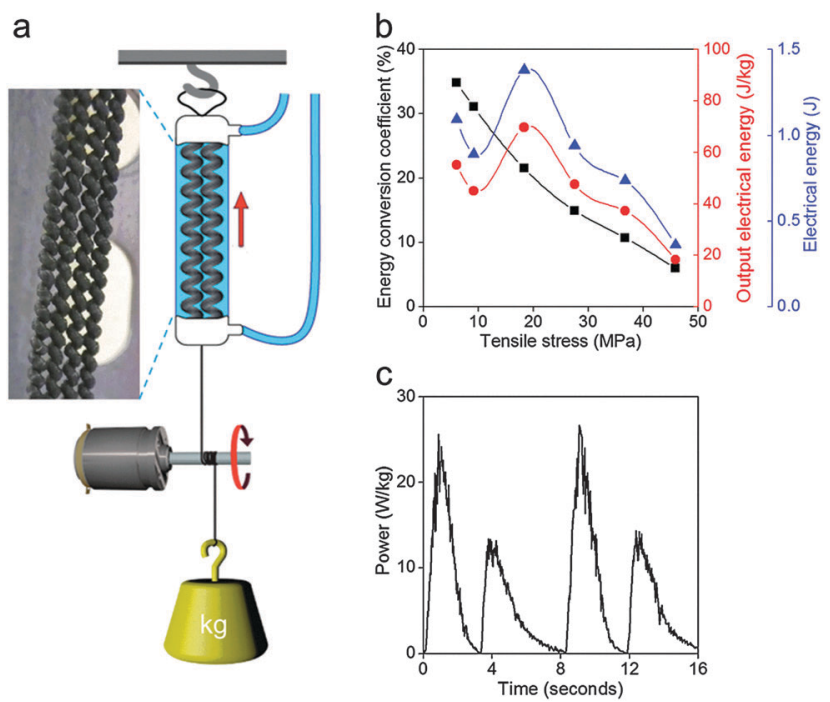

Fig. 5 Electrical energy harvesting using tensile actuation. (a) Illustration of apparatus for using four parallel, coiled $2 \mathrm{~mm}$-diameter polyethylene muscles (photograph in inset) to generate electricity by rotating the shaft of an electric motor in opposite directions during muscle contraction and expansion. Circulation of alternating hot $\left(95^{\circ} \mathrm{C}\right)$ and cold $\left(25^{\circ} \mathrm{C}\right)$ water provided muscle contraction and expansion, respectively, while the attached fixed weight provided muscle tension. (b) The coefficient for gravitational potential energy to electrical energy conversion (black data points), the total output electrical energy per cycle (blue data points), and the gravimetric electric energy output per cycle (red data points, which are normalized to muscle mass) as a function of the applied tensile stress. (c) Time dependence of gravimetric electrical power produced during muscle contraction and muscle expansion during two heating/cooling cycles at $0.125 \mathrm{~Hz}$. Approximately $1.4 \mathrm{~J}$ of electrical energy was produced per cycle for the above results using $45 \mathrm{~cm}$-long coiled muscles. 
Despite the higher gravimetric electrical energy density per cycle for the tensile harvester than for the torsional harvesters, the demonstrated tensile harvester has a diminished average gravimetric power capability per muscle weight $\left(7.2 \mathrm{~W} \mathrm{~kg}^{-1}\right)$ compared with that for torsional harvesters based on coiled $102 \mu \mathrm{m}$-diameter $\left(25.2 \mathrm{~W} \mathrm{~kg}^{-1}\right)$ and $27 \mu \mathrm{m}$-diameter $\left(38.1 \mathrm{~W} \mathrm{~kg}^{-1}\right)$ precursor fibers, which reflects the much larger diameter $(2 \mathrm{~mm})$ of the precursor polyethylene fibers used for the muscle. This power density disadvantage can be eliminated by increasing cycle rate capability (from the present $0.125 \mathrm{~Hz}$, compared with $0.5 \mathrm{~Hz}$ and $1 \mathrm{~Hz}$, respectively, for the latter torsional muscles) by decreasing muscle diameter (and correspondingly increasing the number of muscles in an array). Operating a $27 \mu$ m-diameter fiber torsional muscle using resonant temperature fluctuations provided record gravimetric average electrical power for low $\Delta T$ thermal-to-mechanical-to-electrical energy harvesters: $124 \mathrm{~W} \mathrm{~kg}^{-1}$ for $\Delta T=19.6{ }^{\circ} \mathrm{C}$ and $26.8 \mathrm{~W} \mathrm{~kg}^{-1}$ for $\Delta T=8.2{ }^{\circ} \mathrm{C}$.

Shape memory alloys (SMAs), which have been investigated for over 80 years, are the most important competitor of our newly developed polymer muscles for upscalable thermal energy applications. In an important advance of 2014, a miniature thermal energy harvester was reported in which an actuating NiTi shape memory alloy wire rotates on two pulleys between hot and cold sinks, so as to drive a rotary electrical generator attached to one pulley. ${ }^{9}$ Though the obtained electrical power $(1.7 \mathrm{~mW})$ was much lower than presently realized for the tensile coiled polymer harvester $(56 \mathrm{~mW})$, the use of $300 \mu \mathrm{m}$-diameter NiTi wire, rather than the $2 \mathrm{~mm}$-diameter fiber of the coiled polyethylene muscle, provided a higher power density per muscle weight (14.2 $\mathrm{W} \mathrm{kg}^{-1}$ for $\left.\Delta T \sim 51{ }^{\circ} \mathrm{C}\right)$ than for our polymer-musclepowered tensile energy generator $\left(7.2 \mathrm{~W} \mathrm{~kg}^{-1}\right.$ for $\left.\Delta T \sim 70{ }^{\circ} \mathrm{C}\right)$. The substantially higher gravimetric work per cycle for the polymer tensile harvester $\left(77 \mathrm{~J} \mathrm{~kg}^{-1}\right)$, compared with that for the SMA harvester $\left(17.7 \mathrm{~J} \mathrm{~kg}^{-1}\right)$, indicates the higher ultimate potential of the polymer harvester when operated at comparable cycle rates (by reduction of the diameter of the fiber in the coiled polymer muscle).

Importantly for upscaling generators to harvest the lowgrade thermal energy from combustion engines or industrial waste streams, NiTi alloy wires are presently very expensive $\left(\sim \$ 3200 \mathrm{~kg}^{-1}\right.$ for kilometer lengths of $380 \mu \mathrm{m}$ diameter muscle wires), ${ }^{16}$ compared with the low precursor fiber cost for the coiled polymer muscle $\left(\sim \$ 5 \mathrm{~kg}^{-1}\right.$ for nylon and $\sim \$ 10 \mathrm{~kg}^{-1}$ for polyethylene) and the low cost of inserting twist to produce coiling. Hence, the per-Watt cost of the muscles for the SMA wire harvester might well be over a 100 times those for the tensile polymer harvester, which is a critically important issue for large scale energy generators. Results on an interesting upscaled harvester ${ }^{8}$ using 0.7 mm-thick SMA-sheet belts provided $1.16 \mathrm{~W}$ of electrical power, but the power per muscle weight $\left(4.43 \mathrm{~W} \mathrm{~kg}^{-1}\right)$ was lower than for the present polymer muscle tensile harvester. The use of two or more pulleys to transport actuating wires or belts for the SMA energy harvesters (with diameters necessarily much larger than fiber or belt thickness) means that the volumetric power capacity of these twodimensionally configured SMA harvesters (per occupied volume of power-generating actuators) must be very small compared with that for the described polymer tensile generator, where parallel, proximate polymer muscles form a three-dimensional array.

The tensile harvester can be easily upscaled, without decrease in electrical power and energy output per muscle mass, by operating numerous small diameter muscles in parallel. This strategy could be useful, for instance, for harvesting the waste thermal energy from an internal combustion engine or the temperature difference between hot and cold waste streams that exit a chemical plant. Based on the presently realized average

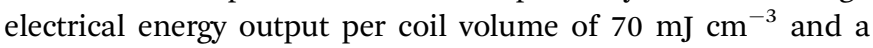
cycle time of $\sim 8$ seconds for tensile actuation, and assuming that muscle volume is $56 \%$ of the total volume of the thermal exchanger for switching muscle temperature, a cubic meter size heat exchanger would provide $4.9 \mathrm{~kW}$ of output electrical power when using a $70{ }^{\circ} \mathrm{C}$ temperature difference in hot and cold waste streams.

\section{Conclusions}

Though present performance is attractive compared with previous solid-state devices for the thermal-to-mechanical-to-electrical harvesting of energy, the realized output electrical energy is only a small fraction of the specific torsional and tensile work capacity of these muscles. Improvements, like reducing the mechanical inertia of the system by replacing the fixed weight with constant force springs, increasing cycle rate by decreasing muscle diameter, increasing the presently low thermal-to-mechanical energy conversion efficiency of the muscles, and optimizing the mechanical match between motor and muscles, might enable over an order of magnitude increase in output electrical power.

\section{Acknowledgements}

This work was supported by the Creative Research Initiative Center for Self-powered Actuation and the Korea-US Air Force Cooperation Program Grant No. 2013K1A3A1A32035592 in Korea. Support at the University of Texas at Dallas was provided by Air Force Office of Scientific Research grants FA9550-15-1-0089, FA955014-1-0227, and FA2386-13-1-4119, NASA grants NNX14CS09P and NNX15CS05C, NSF grant CMMI 1120382, and the Robert A. Welch Foundation grant AT-0029. Additional support was from the Australian Research Council Discovery Grant DP110101073 and the Australian National Fabrication Facility, and a Natural Sciences and Engineering Research Council of Canada Discovery grant.

\section{Notes and references}

1 C. B. Vining, Nat. Mater., 2009, 8, 83-85.

2 C. R. Bowen, J. Taylor, E. LeBoulbar, D. Zabek, A. Chauhan and R. Vaish, Energy Environ. Sci., 2014, 7, 3836-3856.

3 S. P. Alpay, J. Mantese, S. Trolier-McKinstry, Q. Zhang and R. W. Whatmore, MRS Bull., 2014, 39, 1099-1109.

4 C. R. Bowen, H. A. Kim, P. M. Weaver and S. Dunn, Energy Environ. Sci., 2014, 7, 25-44. 
5 M. Ujihara, G. P. Carman and D. G. Lee, Appl. Phys. Lett., 2007, 91, 093508.

6 M. Gueltig, H. Ossmer, M. Ohtsuka, H. Miki, K. Tsuchiya, T. Takagi and M. Kohl, Adv. Energy Mater., 2014, 4, 1400751.

7 K. B. Joshi and S. Priya, Smart Mater. Struct., 2013, 22, 055005.

8 Y. Sato, N. Yoshida, Y. Tanabe, H. Fujita and N. Ooiwa, Electr. Eng., Jpn., 2008, 165, 1157-1163.

9 D. Avirovik, R. A. Kishore, D. Vuckovic and S. Priya, Energy Harvesting and Systems, 2014, 1, 13-18.

10 C. S. Haines, M. D. Lima, N. Li, G. M. Spinks, J. Foroughi, J. D. W. Madden, S. H. Kim, S. Fang, M. J. d. Andrade, F. Göktepe, Ö. Göktepe, S. M. Mirvakili, S. Naficy, X. Lepró, J. Oh, M. E. Kozlov, S. J. Kim, X. Xu, B. J. Swedlove, G. G. Wallace and R. H. Baughman, Science, 2014, 343, 868-872.
11 J. Yuan and P. Poulin, Science, 2014, 343, 845-846.

12 Y. Kobayashi and A. Keller, Polymer, 1970, 11, 114-117.

13 C. L. Choy, F. C. Chen and K. Young, J. Polym. Sci., Polym. Phys. Ed., 1981, 19, 335-352.

14 M. D. Lima, N. Li, M. J. d. Andrade, S. Fang, J. Oh, G. M. Spinks, M. E. Kozlov, C. S. Haines, D. Suh, J. Foroughi, S. J. Kim, Y. Chen, T. Ware, M. K. Shin, L. D. Machado, A. F. Fonseca, J. D. W. Madden, W. E. Voit, D. S. Galvão and R. H. Baughman, Science, 2012, 334, 928-932.

15 K.-Y. Chun, S. H. Kim, M. K. Shin, C. H. Kwon, J. Park, Y. T. Kim, G. M. Spinks, M. D. Lima, C. S. Haines, R. H. Baughman and S. J. Kim, Nat. Commun., 2014, 5, 1-9. 16 Dynalloy price list for bulk orders of over $1 \mathrm{~km}$ lengths of $380 \mu \mathrm{m}$ Flexinol ${ }^{\circledR}$ muscle wire, http://www.dynalloy.com/ flexwire_70_90.php. 